\title{
Inbreeding depression and self-fertilization in Lymnaea peregra (Gastropoda: Pulmonata)
}

\author{
P. Jarne and \\ B. Delay
}

Université Montpellier II,

Institut des Sciences de l'Evolution, Laboratoire "génétique et environnement", Place E. Bataillon, 34000 Montpellier, France.

The effects of self-fertilization and cross-fertilization on several fitness traits were examined in the freshwater hermaphrodite snail Lymnaea peregra. Laboratory strains were established from Lake Geneva populations. Comparisons of F2 snails and their offspring showed that there are no differences in hatching time, nor in the size of young snails monitored over one month. But there was a significant difference, when the distribution of the capsule weight against the number of eggs was compared, although the effects of this on fitness are probably small. There was also a significant difference for egg production and juvenile viability over one month; the selfing snails are 94 per cent less fit for these two traits than the outcrossing.

\section{INTRODUCTION}

Self-fertilization and inbreeding depression have been widely studied, from both a theoretical and an empirical point of view (Lloyd, 1979; Lande and Schemske, 1985; Charlesworth and Charlesworth, 1987; Holsinger, 1988; Schemske and Lande, 1985; Stevens and Bougourd, 1988). Most studies are limited to plants. However, mating systems are as diverse in molluscs as in plants. All pulmonates are hermaphroditic (Duncan, 1975) and numerous Basommatophora species selffertilize. Comparative data on the fitness of individuals in cross-fertilization and self-fertilization are important for understanding the evolution of natural populations. However, few studies have been undertaken in molluscs (Selander and Kaufman, 1973; Selander et al., 1975). We present data on such a comparison at different stages of the life cycle in the Basommatophoran, Lymnaea peregra. The ratio of self-fertilization $v s$. crossfertilization results measures the phenotypic effects of self-fertilization on some components of fitness.

$L$. peregra is a freshwater snail from Europe and West-Asia (Hubendick, 1951). It is a functional self-fertile hermaphrodite (Diver et al., 1925). Boycott et al. (1930) showed that foreign sperm is stored and remains viable for several months after copulation. It is used for crossfertilization. As it becomes exhausted or dies, the self-fertilization rate gradually increases (Duncan, 1975). L. peregra preferentially cross-fertilizes whenever allosperm is available (Boycott et al., 1930). Thus, selfed products must be obtained from individuals which have been isolated when immature.

\section{MATERIALS AND METHODS}

Parent snails were collected on the littoral of Lake Geneva in June 1987. The animals were kept in the laboratory in 3-litre glass tanks. Egg capsules were collected every 3 days. The hatchlings (F1 generation) were reared from these. The capsules of the F1 generation were collected and those designed for self-fertilization were incubated individually in $150 \mathrm{ml}$ plastic boxes. After hatching, young F2 snails were isolated in similar boxes. Capsules designed for the cross-fertilization study were incubated in 3-litre glass tanks. Thirty young snails at the most were reared per tank. The data on inbreeding depression were obtained on the F2 generation and their offspring. Throughout the study, all snails were maintained at $20^{\circ} \mathrm{C}$ with an artificial photoperiod of $16 \mathrm{~L} / 8 \mathrm{D}$. They were fed with lettuce and water was changed about every 3 days.

In Experiment 1, the oviposition rate and the capsule weight of F2 snails are compared. The 
study was conducted on 12 selfing snails and four groups of 10 outcrossing snails. The capsules (F3 generation) were collected over 40 days. As the number of individuals and oviposition rate was higher in cross-fertilization, only 200 randomly chosen capsules were used in the analysis. The number of eggs per capsule was counted and the capsules were desiccated at $70^{\circ} \mathrm{C}$ for 24 hours before they were weighed to an accuracy of $1 / 1000 \mathrm{mg}$.

The number of eggs per capsule and the weight of the egg capsules were log-transformed to stabilize the variance. Mean egg numbers were compared between outcrossed and selfed capsules with a $t$-test. The oviposition rate was calculated as the number of eggs and the number of capsules per snail and per day. For all data and data of each mating system, the capsule weight was plotted against the number of eggs per capsule. The linear correlation coefficient $r$ of these distributions was calculated in a regression analysis. The null hypothesis " $r=0$ " was tested as a $t$-test. Analyses of covariance (ANCOVA) were performed to compare the regressions between the two mating systems and also among different tanks in crossfertilization.

In Experiment 2, hatching time, hatchability, size at birth, survival and size at 14 and 30 days were compared between selfed and outcrossed F2 offspring. The partition of snails is the same as in Experiment 1, except that 10 snails only were used for self-fertilization. The capsules were collected every 2 days for 16 days. Only a quarter of the outcrossed capsules, randomly chosen among those laid, were studied, because of the high productivity of the outcrossing groups. The number of eggs per capsule $N_{\mathrm{ec}}$ was counted and each capsule was then checked every 2 days during 2 weeks after hatching of the first snail (time $t_{1}$ ). We noted:

(1) the hatching time $t_{j}$ for all individuals and the hatchability $S_{0 \mathrm{c}}$ for all capsules.

$$
S_{0 \mathrm{c}}=\left(N_{\mathrm{oc}} / N_{\mathrm{ec}}\right) * 100
$$

where $N_{0 c}$ is the number of hatchlings per capsule.

The mean hatching time $T_{m}$ for each capsule was:

$$
T_{m}=\sum_{j=1}^{k} n_{j} \cdot t_{j} / \sum_{j=1}^{k} n_{j}
$$

with $n_{j}$ snails hatching at time $t_{j}$ and $k=$ number of hatching observations.
The size at birth of three haphazardly individuals chosen per capsule was measured. When less than three individuals were available, particularly for self-fertilization, only one or two individuals were measured. $T_{0}$ is the date corresponding to the mean hatching time.

(2) The percentages of survivors $S_{1 \mathrm{c}}$ and $S_{2 \mathrm{c}}$ and size of three of them at respectively $T_{1}$ and $T_{2}$.

$$
\begin{aligned}
& S_{1 \mathrm{c}}=\left(N_{1 \mathrm{c}} / N_{0 \mathrm{c}}\right) * 100 \\
& S_{2 \mathrm{c}}=\left(N_{2 \mathrm{c}} / N_{1 \mathrm{c}}\right) * 100
\end{aligned}
$$

where $N_{1 \mathrm{c}}$ and $N_{2 \mathrm{c}}$ are the number of survivors. $T_{1}$ and $T_{2}$ are respectively on average 14 and 30 days after $T_{0}$.

Before the statistical analyses, the size data were log-transformed. Mean hatching time, hatchability and size at $T_{0}, T_{1}$ and $T_{2}$ were compared among and within mating system in a nested analysis of variance (ANOVA) with unequal sample size. To analyse survival data, we performed a nested ANOVA on the survival logit using a variance proportional to a binomial variance with a quasi-likelihood model (McCullagh and Nelder, 1983). Except for this last ANOVA, all the analysis in Experiments 1 and 2 were performed following Sokal and Rohlf (1981).

\section{Inbreeding depression estimates}

In Experiments 1 and 2, several fitness components were estimated at different stages of the life cycle of snails (egg-laying rate of the parerits, survival and size of the offspring). When the parameters measured were significantly different between selffertilization and cross-fertilization, they were used to estimate the inbreeding depression (see Lande and Schemske, 1985; Charlesworth and Charlesworth, 1987):

$$
d_{j}=1-w_{1}(j) / w_{0}(j)
$$

with $w_{1}(j)=$ mean performance in self-fertilization for parameter $j$ and $w_{0}(j)=$ mean performance in cross-fertilization for the same parameter.

The overall difference between the two mating systems was calculated as:

$$
d=1-\prod_{j=1}^{k} w_{1}(j) / w_{0}(j)
$$

with $k=$ number of parameters considered. 


\section{RESULTS}

\section{Experiment 1}

The mean number of eggs per capsule (table 1) is greater in cross-fertilization than in self-fertilization $\left(t_{315}=16.9, P<0.01\right)$. The number of eggs and the number of egg capsules per snail and per day are given in table 1 . The linear correlation coefficients between the number of eggs and the dry weight of capsules are given in table 2 . As 90 per cent of the selfed capsules have less than 15 eggs ( 60 per cent in cross-fertilization), we also computed the correlation coefficient for these capsules separately. All the correlation coefficients are significantly different from zero (table 2 ).

The ANCOVA shows a significant difference when regressions for the two mating systems are compared (table 2). However, the difference is not significant when capsules with less than 15 eggs are considered. In this case, as for data from crossfertilization, the second step of ANCOVA was

Table 1 Egg capsule characteristics and oviposition rates. $n$ is the mean number of eggs per capsule and $\sigma(n)$ its standard deviation

\begin{tabular}{llrl}
\hline Mating system & & Cross-F & Self-F \\
\hline Number of eggs & $n$ & 13.54 & 7.59 \\
$\quad$ / capsule & $\sigma(n)$ & 8.71 & 7.93 \\
$\begin{array}{l}\text { Number of eggs } \\
\quad \text { snail/day }\end{array}$ & 3.64 & 1.85 \\
$\begin{array}{l}\text { Number of egg capsules } \\
\quad \text { /snail/day }\end{array}$ & 0.27 & 0.25 \\
\hline
\end{tabular}

performed (table 2) which showed that the hypothesis of single regression could not be accepted. The regressions for cross-fertilization and selffertilization are presented in figs. 1 and 2 respectively.

\section{Experiment 2}

Numerous selfed capsules did not hatch and survival at $T_{1}$ and $T_{2}$ was very low. Thus, for the size analysis, all the data from self-fertilization were taken into account, whereas only one randomly chosen individual per outcrossed capsule among the three measured was considered. Hatching time and size are given in table 3 . The results of the nested ANOVA comparing these parameters between the two mating systems showed that there are no significant differences at any stage (table 4). $F$-values for the subdivisions within systems are significant at $T_{1}$ and $T_{2}$ showing that there is some variance between the cross-fertilization groups. Survival data are given in table 3. Outcrossed snails survived significantly better than selfed ones (ANOVA, table 5). There are no differences between the outcrossed groups.

\section{Inbreeding depression estimates}

We calculated the results of self-fertilization versus cross-fertilization snails. Data for hatching time and size were not included, as there was no significant difference between mating systems. $1-d_{j}$ and $d_{j}$ values for each stage are given in table 3 . The overall coefficient estimating the inbreeding

Table 2 Correlation coefficients between the number of eggs per capsule and the capsule weight and analysis of covariance $F$-values. The number of degrees of freedom is given in italics below each value

\begin{tabular}{|c|c|c|c|}
\hline & \multirow[b]{2}{*}{$\begin{array}{l}\text { Correlation } \\
\text { coefficient }\end{array}$} & \multicolumn{2}{|c|}{ ANCOVA $F$-values } \\
\hline & & $\begin{array}{l}\text { Homogeneity } \\
\text { of slopes }\end{array}$ & $\begin{array}{l}\text { Single } \\
\text { regression }\end{array}$ \\
\hline All capsules & $\begin{array}{l}0 \cdot 891^{* * * *} \\
314\end{array}$ & $\begin{array}{l}29 \cdot 4^{* * *} \\
1,312\end{array}$ & - \\
\hline Capsules $<15$ eggs & $\begin{array}{l}0 \cdot 789^{* * * *} \\
222\end{array}$ & $\begin{array}{l}1.4 \mathrm{~ns} \\
1,220\end{array}$ & $\begin{array}{l}17 \cdot 6^{* * *} \\
1,221\end{array}$ \\
\hline Cross-fertilization capsules & $\begin{array}{l}0 \cdot 901^{* * * *} \\
197\end{array}$ & $\begin{array}{l}2 \cdot 4 \mathrm{~ns} \\
3,191\end{array}$ & $\begin{array}{l}35 \cdot 2^{* * *} \\
3,194\end{array}$ \\
\hline Self-fertilization capsules & $\begin{array}{l}0 \cdot 879^{* * *} \\
115\end{array}$ & & \\
\hline
\end{tabular}

\footnotetext{
$*=P<0.05$.

$* *=P<0.01$.

$* * *=P<0.001$.

$\mathrm{ns}=$ non-significant.
} 


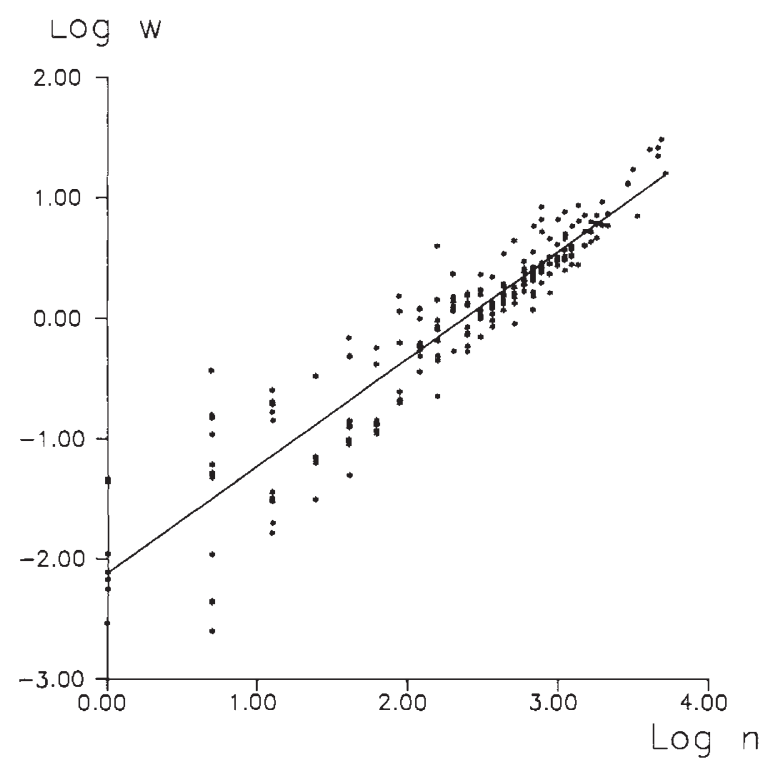

Figure 1 Variation of the logarithm of the dry weight according to the logarithm of the number of eggs in cross-fertilization. $n$ is the number of eggs per capsule and $w$ is the dry weight (in $\mathrm{mg}$ ) of a capsule. The equation of the regression line is: $y=0.888 x-2 \cdot 118$.

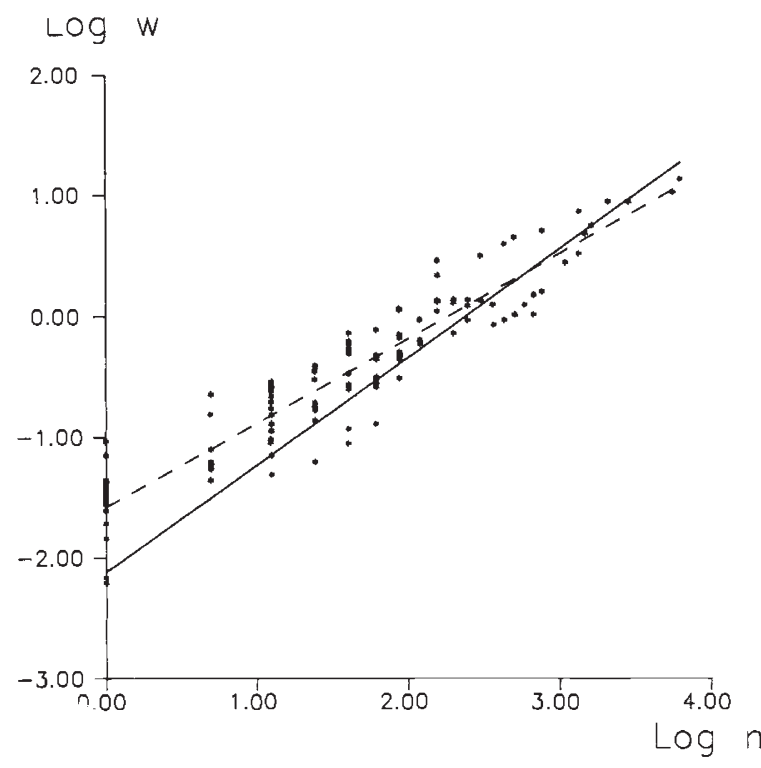

Figure 2 Variation of the logarithm of the dry weight according to the logarithm of the number of eggs in self-fertilization. The equation of the regression line (dashed line) is: $y=$ $0.695 x-1.580$. The regression line for cross-fertilization data is superimposed as a continuous line.

Table 3 Results of cross-fertilization and self-fertilization for the two experiments and their standard deviation in italics. $1-d_{j}$ is the relative performance of selfed versus outcrossed hatchlings. $d$ and $1-d$ are calculated over all stages showing a significant difference between the mating systems. $T_{0}$ is the date corresponding to the mean hatching time. $T_{1}$ and $T_{2}$ are respectively 14 and 30 days after $T_{0}$

\begin{tabular}{|c|c|c|c|c|c|c|c|}
\hline & & \multicolumn{2}{|c|}{ Cross-F } & \multicolumn{2}{|l|}{ Self-F } & \multirow{2}{*}{$\frac{1-d_{j}}{0 \cdot 508}$} & \multirow{2}{*}{$\frac{d_{j}}{0.492}$} \\
\hline & er of eggs/snail/day & $3 \cdot 64$ & & $1 \cdot 85$ & & & \\
\hline$T_{0}$ & $\begin{array}{l}\text { Hatching time } T_{\mathrm{c}} \text { (days) } \\
\text { Hatchability } S_{0 \mathrm{c}} \\
\text { Size }(\mathrm{mm})\end{array}$ & $\begin{array}{l}14 \cdot 56 \\
0 \cdot 793 \\
1 \cdot 723\end{array}$ & $\begin{array}{l}1 \cdot 37 \\
0 \cdot 198 \\
0 \cdot 117\end{array}$ & $\begin{array}{l}14 \cdot 55 \\
0 \cdot 307 \\
1 \cdot 671\end{array}$ & $\begin{array}{l}2 \cdot 33 \\
0 \cdot 266 \\
0 \cdot 130\end{array}$ & $\begin{array}{l}- \\
0 \cdot 387 \\
-\end{array}$ & $\begin{array}{l}- \\
0.613\end{array}$ \\
\hline$T_{1}$ & $\begin{array}{l}\text { Survival } S_{1 \mathrm{c}} \\
\text { Size }(\mathrm{mm})\end{array}$ & $\begin{array}{l}0.770 \\
2 \cdot 981\end{array}$ & $\begin{array}{l}0.195 \\
0.772\end{array}$ & $\begin{array}{l}0.409 \\
2 \cdot 405\end{array}$ & $\begin{array}{l}0.413 \\
0.648\end{array}$ & $\begin{array}{l}0.531 \\
-\end{array}$ & $\begin{array}{l}0.469 \\
-\end{array}$ \\
\hline$T_{2}$ & $\begin{array}{l}\text { Survival } S_{2 \mathrm{c}} \\
\text { Size }(\mathrm{mm})\end{array}$ & $\begin{array}{l}0.837 \\
4 \cdot 315\end{array}$ & $\begin{array}{l}0.226 \\
0.976\end{array}$ & $\begin{array}{l}0.478 \\
3.634\end{array}$ & $\begin{array}{l}0 \cdot 467 \\
1 \cdot 212\end{array}$ & $\begin{array}{l}0.571 \\
-\end{array}$ & $\begin{array}{l}0.429 \\
-\end{array}$ \\
\hline & Overall & & & & & 0.060 & 0.940 \\
\hline
\end{tabular}

depression is 0.940 one month after hatching (table $3)$.

\section{DISCUSSION}

In some plant species, seed weight is a good indicator of seed viability and seedling growth rate (Stanton, 1984), although Stevens and Bougourd (1988) did not find such a relation in Allium schoenoprasum. We compared cross-fertilization and self-fertilization to find out whether there was a different weight investment in capsules in $L$. peregra.

In all cases, the linear correlation coefficient between the number of eggs and the dry weight of a capsule was high and significantly different from zero. This indicates that the correlations are effectively linear. The ANCOVA showed a difference between outcrossed and selfed capsules. However, when the egg capsules with more than 15 eggs are discarded, the hypothesis of 
Table 4 Results of the nested ANOVA on hatching time and size between and within the two mating systems. The number of degrees of freedom is given in italics below each value

\begin{tabular}{|c|c|c|c|c|}
\hline \multicolumn{2}{|c|}{$\begin{array}{l}\text { Source of } \\
\text { variation }\end{array}$} & $\begin{array}{l}\text { Mating } \\
\text { system }\end{array}$ & $\begin{array}{l}\text { Subdivisions } \\
\text { within systems }\end{array}$ & Residuals \\
\hline \multicolumn{2}{|c|}{ Hatching time } & $\begin{array}{l}0 \cdot 272 \mathrm{~ns} \\
1\end{array}$ & $\begin{array}{l}0 \cdot 105 \mathrm{~ns} \\
4\end{array}$ & 94 \\
\hline$T_{0}$ & Size & $\begin{array}{l}3 \cdot 961 \mathrm{~ns} \\
1\end{array}$ & $\begin{array}{l}2 \cdot 119 \mathrm{~ns} \\
4\end{array}$ & 101 \\
\hline$T_{1}$ & Size & $\begin{array}{l}1.837 \mathrm{~ns} \\
1\end{array}$ & $\begin{array}{l}8 \cdot 078^{* * *} \\
4\end{array}$ & 99 \\
\hline$T_{2}$ & Size & $\begin{array}{l}1 \cdot 354 \mathrm{~ns} \\
1\end{array}$ & $\begin{array}{l}3 \cdot 522^{*} \\
4\end{array}$ & 85 \\
\hline
\end{tabular}

$*=P<0.05$.

$* * *=P<0.001$.

ns $=$ non-significant

Table $5 F$-values obtained in the nested ANOVA comparing survival between and within the two mating systems. The number of degrees of freedom is given in italics below each value

\begin{tabular}{lll}
\hline Time & Mating system & $\begin{array}{l}\text { Subdivisions } \\
\text { within systems }\end{array}$ \\
\hline$T_{0}$ & $79 \cdot 677^{* * *}$ & $0 \cdot 680 \mathrm{~ns}$ \\
& 1,119 & 1,115 \\
$T_{1}$ & $32 \cdot 774^{* * *}$ & $2 \cdot 110 \mathrm{~ns}$ \\
& 1,108 & 1,104 \\
$T_{2}$ & $79 \cdot 057^{* * *}$ & $3 \cdot 880 \mathrm{~ns}$ \\
& 1,920 & 1,880 \\
\hline
\end{tabular}

$* * *=P<0.001$.

$\mathrm{ns}=$ non-significant.

homogeneity of slopes can be accepted, although the regression lines are not superimposed. Above 15 eggs, outcrossed capsules are heavier while below the opposite is true (see fig. 2). Comparison between tanks in cross-fertilization produced no difference for the homogeneity of slopes. However, the rejection of the hypothesis of single regression shows that some variability remains, even if the difference between mating systems is higher than within cross-fertilization.

In Lymnaea species, no data are available on the weight of the encapsulating structures relative to the weight of the capsules (= encapsulating structures + eggs). Nevertheless, it is likely that this ratio never reaches more than a few per cent. It is higher for the smallest capsules and also for the selfed capsules when compared to the outcrossed. The difference in weight could therefore be due to differences in the encapsulating structure volume in the case of the smallest capsules (e.g., below five eggs). For more than 15 eggs, selfed capsules may be lighter than outcrossed. Even if there is an actual slight difference in capsule weight, the eggs of one mating system are not systematically heavier. It seems that the differential survival is not due to a differential weight investment in eggs and that egg weight is a poor indicator of viability.

In the second experiment, there was no significant difference in hatching time. The higher mortality does not seem to be due to a too short development time within the selfed capsules. There was also no apparent difference in size at birth, $T_{1}$ and $T_{2}$. Due to the lower number of eggs per selfed capsule and the higher mortality, the density in self-fertilization rearing boxes was lower which should have contributed to a faster growth, because there is a negative correlation between growth and density in Basommatophora (Chaudhry and Morgan, 1987; Loreau and Baluku, 1987). Surviving selfed snails grew as quickly as outcrossed ones which suggests that the difference lies in offspring survival rather than in growth.

The mean number of eggs per capsule is twice as high in cross-fertilization as in self-fertilization. The number of capsules per snail and per day, however, is not different. Selfing snails are then less able to lay eggs than their outcrossing counterparts. The viability of the selfed offspring at one month is 12 per cent of that of the outcrossed (see table 3). At birth, the difference is not due to a different number of eggs aborting at the first stages of egg division, but rather to a higher number of well formed hatchlings which did not hatch. The coefficient which combines differential egg-laying rate and survival at one month of outcrossed and 
selfed snails was $0 \cdot 940$. Thus, self-fertilization appeared to be disadvantageous in the first generation, for these parameters.

Colton and Pennypacker (1934) published the results of 20 years of self-fertilization in $L$. columella. They stated that: "This race shows remarkable hardiness. Rarely does an egg once laid and kept under favourable conditions fail to hatch". However, no data were given. Cain (1956) obtained a 64.7 per cent hatchability and 92.9 per cent of the snails survived over 6 days for selfed hatchlings in $L$. stagnalis. Similarly, Paraense (1955) and Vianey-Liaud (1989) obtained a survival at birth of around 80 per cent in selfing Biomphalaria glabrata. These results are all higher than ours. However, in these studies, no data are presented for cross-fertilizing snails which precludes any comparative analysis. Moreover, keeping a laboratory strain under self-fertilization may select for limited inbreeding depression. The mechanism is similar to the bottleneck effect invoked by Lande and Schemske (1985) and Charlesworth and Charlesworth (1987) for the introduction of self-fertilization in self-fertile outcrossing species. Self-fertilization can then be maintained for many generations. In the studies for which a comparison is possible, the ratio of self-fertilization/cross-fertilization for the egglaying rate was 0.687 in Bulinus cernicus (Rollinson et al., 1989), a smaller inbreeding effect than ours. Selander and Kaufman (1973) and Selander et al. (1975) found no depression for self-fertilization in the stylommatophoran Rumina decollata, and even an advantage in some cases. However, none of these studies give data on the viability of the offspring, although it constitutes one of the parameter of fitness.

For natural plant populations, there may be a bimodal distribution of outcrossing rates, with some species preferentially selfing and others outcrossing, representing alternate stable states of the mating system (Schemske and Lande, 1985). Lloyd (1979) and Lande and Schemske (1985) suggested that in historically large outcrossing populations with a substantial inbreeding depression, selection acts in favour of outcrossing. Self-fertilization could be favoured when populations suffer severe bottlenecks, even if inbreeding depression is quite high (Charlesworth and Charlesworth, 1987). In our study, the effect of selfing was so strong that it is likely to play a minor role in Lake Geneva natural populations, and selfing probably occurs only when a bottleneck is involved, such as when a self-fertilizing snail is isolated before copulation; in spite of a great fitness drop, the continuity of the population is then ensured. Whether selffertilization will consequently be maintained is uncertain, although it is possible. If an individual has copulated at least once, it will, before selfing, exhaust its allosperm and thus function as a crossfertilizer for some time. Additional studies are needed to estimate how important a single copulation is on the inbreeding depression resulting from a subsequent self-fertilization.

Acknowledgements We thank M. Vianey-Liaud, I. Olivieri, F. Kjellberg and J. Britton-Davidian who improved the first version of the manuscript. Many thanks are due to P. Blanc and to G. Chapuis for technical help. J. D. Lebreton provided statistical advice. We are also grateful to the referees. The research was supported by INRA-Département d'Hydrobiologie and URA 327, CNRS-USTL funds.

\section{REFERENCES}

BOYCOTT, A. E., DIVER, C., GARSTANG, S. AND TURNER, F. M. 1930. The inheritance of sinistrality in Limnaea peregra. Phil. Trans. Roy. Soc. London, Ser. B, 219, 51-131.

CAIN, G. L. 1956. Studies on cross-fertilization and self-fertilization in Lymnaea stagnalis appressa Say. Biol. Bull., 111, 45-52.

CHARLESWORTH, D. AND CHARLESWORTH, B. 1987. Inbreeding depression and its evolutionary consequences. Ann. Rev. Ecol. Syst., 18, 237-268.

CHAUDHRY, A. M. AND MORGAN, E. 1987. Factors affecting the growth and fecundity of Bulinus tropicus (Krauss) (Gastropoda). J. Moll. Stud., 53, 52-61.

COLTON, H. S. AND PENNYPACKER, M. 1934. The results of twenty years of self-fertilization in the pond snail Lymnaea columella Say. Am. Nat., 68, 129-136.

DIVER, C., BOYCOTT, A. E. AND GARSTANG, S. 1925. The inheritance of inverse symmetry in Lymnaea peregra. $J$. Genetics, 15, 113-200.

DUNCAN, C. J. 1975. Reproduction. In Fretter, V. and Peake, J. (eds) Pulmonates, Vol. 1, Functional Anatomy and Physiology, Academic Press London, pp. 309-365.

HOLSINGER, K. E. 1988. Inbreeding depression doesn't matter: the genetic basis of mating-system evolution. Evolution, 42, 1235-1244.

HUBENDICK, B. 1951. Recent Lymnaeidae: their variation, morphology, taxonomy, nomenclature, and distribution. Kungl. Svenska Ventenskapsakademiens Handlingar, 3, $1-225$.

LANDE, R. AND SCHEMSKE, D. W. 1985. The evolution of self-fertilization and inbreeding depression in plants. I. Genetic models. Evolution, 39, 24-40.

LLOYD, D. G. 1979. Some reproductive factors affecting the selection of self-fertilization in plants. Am. Nat., 113,67-79.

LOREAU, M. AND BALUKU, B. 1987. Growth and demography of populations of Biomphalaria pfeifferi (Gastropoda, Planorbidae) in the laboratory. J. Moll. Stud., 53, 171-177.

McCUllaGH, P. AND NELDER, J. A. 1983. Monographs on Statistics and Applied Probability. Chapman \& Hall, Cambridge University Press.

PARAENSE, W. L. 1955. Self- and cross-fertilization in Australorbis glabratus. Mem. Inst. Oswaldo Cruz, 53, 285-291. 
ROLlinSON, D., KANE, R. A. AND LINES, J. R. L. 1989. An analysis of fertilization in Bulinus cernicus (Gastropoda: Planorbidae). J. Zool., London, 217, 295-310.

SCHEMSKE, D. W. AND LANDE, R. 1985. The evolution of self-fertilization and inbreeding depression in plants. II. Empirical observations. Evolution, 39, 41-52.

SELANDER, R. K. AND KAUFMAN, D. W. 1973. Self-fertilization and genetic population structure in a colonizing land snail. Proc. Natl Acad. Sci. USA, 70, 1186-1190.

SELANDER, R. K., KAUFMAN, D. W. AND RALIN, R. S. 1975. Self-fertilization in the terrestrial snail Rumina decollata. The Veliger, 16, 265-270.

SOKAL, R. R. AND ROHLF, F. J. 1981. Biometry, 2nd edn. Freeman.
STANTON, M. L. 1984. Seed variation in wild radish: effects of seed size on components of seedling and adult fitness. Ecology, 65, 1105-1112.

STEVENS, J. P. AND BOUGOURD, S. M. 1988. Inbreeding depression and the outcrossing rate in natural populations of Allium schoenoprasum L. (Wild chives). Heredity, 60, 257-261.

VIANEY-LIAUD, M. 1989. Growth and fecundity in a blackpigmented and an albino strain of Biomphalaria glabrata (Gastropoda: Pulmonata). Malacological Review, 22, $25-$ 32. 